\title{
RESPON PERTUMBUHAN DAN PRODUKSI ROSELLA (Hibiscus sabdariffa L.) PADA TANAH SALIN DENGAN PEMBERIAN ASAM SALISILAT DAN GIBERELLIN (GA3)
}

\author{
Aisar Novita ${ }^{1 *}$, Luthfi A.M .Siregar ${ }^{2}$, dan Rosmayati \\ ${ }^{1}$ Program Studi Agroekoteknologi, Fakultas Pertanian, UMSU, Medan, 20238 Indonesia \\ ${ }^{2}$ Program Studi Agroekoteknologi, Fakultas Pertanian, Universitas Sumatera Utara, Medan \\ Corresponding author: aisar_novita@yahoo.com
}

\begin{abstract}
ABSTRAK
Penelitian ini bertujuan untuk mengevaluasi respon pertumbuhan dan produksi rosella (hibiscus sabdariffa L.) pada tanah salin dengan pemberian asam salisilat dan giberellin (GA3). Penelitian ini dilakukan di rumah kaca, Fakultas Pertanian, Universitas Sumatera Utara, Medan, pada Februari 2014 sampai Juni 2014. Penelitian menggunakan Rancangan Acak Lengkap (RAL) dengan 3 (tiga) factor dan 3 (tiga) ulangan. Faktor pertama giberellin $\left(\mathrm{GA}_{3}\right)$ dengan dua taraf yaitu $0 \mathrm{mg} \mathrm{L}^{-1}, 5 \mathrm{mg} \mathrm{L}^{-1}$. Faktor kedua asam salisilat dengan tiga taraf yaitu $0 \mathrm{mM}, 0,5 \mathrm{mM}, 1 \mathrm{mM}$. Faktor ketiga tingkat salinitas dengan 2 taraf yaitu $0 \mathrm{dsm}^{-1}$ dan $4-5 \mathrm{dsm}^{-}$ 1. Hasil penelitian menunjukkan bahwa interaksi antara giberellin dan cekaman salinitas memperlihatkan pengaruh nyata pada peubah pertumbuhan seperti persentase perkecambahan, tebal kutikula dan betakaroten. Interaksi antara perlakuan asam salisilat dan cekaman salinitas memperlihatkan pengaruh nyata pada tebal kutikula dan betakaroten. Interaksi tiga factor perlakuan giberellin, asam salisilat dan cekaman salinitas menunjukkan pengaruh yang nyata pada peubah tebal kutikula dan betakaroten.
\end{abstract}

Key words :cekaman salinitas, giberellin, asam salisilat, Hibiscus sabdariffa.

\section{PENDAHULUAN}

Rosella sebagian besar ditanam di India, Afrika, Meksiko, dan zona tropis dan memiliki posisi khusus dalam pengobatan tradisional. Berguna untuk mengontrol tekanan darah, sebagai stimulator seksual, hidangan pembuka untuk selera makan, pemulihan kesehatan, penyegar, pelindung kanker, anti batuk dan minuman pendingin (Lin et al. 2007; Chen et al. 2002; Morton. 1987).

Moosavi et al. (2013) melaporkan bahwa cekaman salinitas berdampak buruk terhadap laju perkecambahan, persentase perkecambahan, kecambah panjang, panjang tunas dan indeks viabilitas benih rosella (Hibiscus sabdariffa). Salinitas merupakan masalah yang meluas di seluruh dunia (Soltani et al. 2006). Salinitas telah mencapai tingkat $19,5 \%$ dari seluruh lahan irigasi pertanian di seluruh dunia (FAO. 2005). Di Indonesia, diperkirakan memiliki
40-43 juta ha lahan bermasalah dan 13,2 juta ha dari lahan tersebut terpengaruh salinitas (Departemen Pekerjaan Umum. 1997). Salah satu faktor abiotik yang paling penting yang membatasi perkecambahan dan pertumbuhan bibit adalah cekaman air yang disebabkan kekeringan dan salinitas (Almansouri et al.2001).

Upaya untuk meningkatkan produksipada kondisi cekaman dilakukan dengan cara perbaikan tanaman sebagian besar tidak berhasil, terutama karena multigenik (karakteristik dikendalikan oleh banyak gen) asal respon adaptif (pengaruh yang cocok).Oleh karena itu, pendekatan yang berfokus menggabungkan aspekaspek fisiologis, biokimia dan metabolik molekul toleransi garamsangat penting untuk mengembangkan varietas tanaman toleran.Salah satu diantaranya adalah hormon tanaman (asam giberelat, asam jasmonat, brassinosterioids, asam salisilat, dll) (Hasanuzzaman et al. 2013). 
Asam salisilat berpengaruh melindungi pengembangan program antistress dan percepatan prosesnormalisasi pertumbuhan setelah menghilangkan faktor stres (Sakhabutdinova et al. 2003). Beberapa studi menunjukkan bahwa aplikasi asam salisilat $(0,5 \mathrm{mM})$ dapat mempromosikan pembentukan ROS pada jaringan fotosintesis dan meningkatkan kerusakan oksidatif selama cekaman garam dan tekanan osmotik (Barba-Espin et al.2011).Yusuf et al. (2012) melaporkan bahwa SA meningkatkan tingkat sistem antioksidan (SOD, CAT dan POX ) baik dalam kondisi stres dan tidak stres.

Tujuan penelitian ini adalah untuk mengevaluasi pengaruh pemberian gibberellin dan asam salisilat terhadap pertumbuhan rosella (Hibiscus sabdariffa L.) pada kondisi cekaman salinitas.

\section{BAHAN DAN METODE}

Penelitian ini dilaksanakan di Rumah Kaca, Fakultas Pertanian, Universitas Sumatera Utara, Medan, pada Februari 2014 sampai Juni 2014.Rancangan yang digunakan dalam penelitian ini adalah Rancangan Acak Lengkap (RAL) dengan menggunakan 3 faktor, yaitu Giberellin $\left(\mathrm{GA}_{3}\right)(\mathrm{A})$, Asam Salisilat (B) dan Cekaman Salinitas $(\mathrm{C})$. Perlakuan Giberellin $\left(\mathrm{GA}_{3}\right)$ terdiri dari 2 taraf: 0 dan $5 \mathrm{mg} \mathrm{L}^{-1}$. Perlakuan Asam Salisilat terdiri dari 3 taraf: 0, 0,5, $1 \mathrm{mM}$. Perlakuan tingkat Salinitas EC terdiri atas 2taraf: 0 dan 4-5 dsm ${ }^{-1}$.

Pelaksanaan Penelitian: Sebelum dikecambahkan benih didesinfeksi dengan alkohol $70 \%$ (selama 10 detik), natrium hipoklorit $10 \%$ (selama 60 detik) (Saghatoleslami. 2010).Benih dipisahkan antara yang diberi perlakuan $\mathrm{GA}_{3}$ dan tanpa perlakuan $\mathrm{GA}_{3}$. Benih direndam dalam 500 $\mathrm{ml}$ aquadest selama 12 jam (tanpa perlakuan $\mathrm{GA}_{3}$ ), dan benih direndam dalam $500 \mathrm{ml}$ larutan perlakuan $\mathrm{GA}_{3}$ selama 12 jam kemudian dikering udarakan (Sundstrom et al. 1987).
Peubah yang diamati: persentase perkecambahan, luas daun spesifik, tebal kutikula, betakaroten dan indeks panen.

\section{HASIL DAN PEMBAHASAN}

\section{Pengaruh Interaksi Antara Giberellin Dan Cekaman Salinitas Terhadap Pertumbuhan Rosella}

Pemberian giberellin pada kondisi cekaman salinitas memperlihatkan pengaruh nyata pada peubah pertumbuhan dan produksi seperti persentase perkecambahan, tebal kutikula dan betakaroten (Tabel). Pemberian giberellin (5 mg L ${ }^{-1}$ ) pada kondisi cekaman salinitas pada tanaman rosella membantu mempertahankan keberhasilan perkecambahan walaupun tebal kutikula, menurun dan tidak terbentuk bunga (fase generatif) untuk dipanen. Hal ini disebabkan karena gibberellin diberikan pada saat perendaman benih yang difokuskan untuk mempertahankan keberhasilan perkecambahan. Pada penelitian ini sebagian dari tanaman rosella yang mendapatkan perlakuan cekaman salinitas mengalami kematian sehingga menurunkan rataan tebal kutikula, namun jika dilihat dari rataan tanaman yang mampu bertahan dihasilkan peningkatan tebal kutikula yang paling tebal terdapat pada tanaman rosella yang mendapat perlakuan cekaman salinitas. Magome et al. (2004) bahwa gibberellin dapat meningkatkan perkecambahan, perluasan daun, perpanjangan batang dan pembungaan pada tanaman Arabidopsis. Hal ini tidak sejalan dengan hasil penelitian Hajibagheri et al. (1983), yang menyatakan bahwa pengamatan pada salinitas yang tinggi secara signifikan meningkatkan ketebalan kutikula. 
Tabel Rata-rata Persentase Perkecambahan, Luas Daun Spesifik, Tebal Kutikula, Klorofil A dan B Warna Bunga, Indeks Panen pada Perlakuan Interaksi Giberellin, Asam Salisilat, dan Cekaman Salinitas pada Tanaman Rosella

\begin{tabular}{|c|c|c|c|c|}
\hline Perlakuan & $\begin{array}{c}\text { Persentase } \\
\text { Perkecambahan }\end{array}$ & $\begin{array}{c}\text { Beta } \\
\text { karoten }\end{array}$ & $\begin{array}{c}\text { Tebal } \\
\text { Kutikula }\end{array}$ & Indeks Panen \\
\hline \multicolumn{5}{|c|}{ Interaksi Giberellin dan Cekaman Salinitas } \\
\hline $\mathrm{A} 0 \mathrm{C} 0$ & $100,000 \mathrm{a}$ & $3.491 \mathrm{~b}$ & $68,453 \mathrm{a}$ & 0.274 \\
\hline A0C1 & $88,890 \mathrm{~b}$ & - & - & - \\
\hline $\mathrm{A} 1 \mathrm{C} 0$ & $100,000 \mathrm{a}$ & $3.547 \mathrm{a}$ & $51,897 \mathrm{c}$ & 0.343 \\
\hline $\mathrm{A} 1 \mathrm{C} 1$ & $100,000 \mathrm{a}$ & - & $57,633 \mathrm{~b}$ & - \\
\hline \multicolumn{5}{|c|}{ Interaksi Asam Salisilat dan Cekaman Salinitas } \\
\hline $\mathrm{B} 0 \mathrm{C} 0$ & & $3.469 \mathrm{~b}$ & $57,085 \mathrm{c}$ & 0.276 \\
\hline $\mathrm{B} 0 \mathrm{C} 1$ & & - & $46,550 \mathrm{~d}$ & - \\
\hline $\mathrm{B} 1 \mathrm{C} 0$ & & $3.789 \mathrm{a}$ & $62,225 \mathrm{a}$ & 0.294 \\
\hline $\mathrm{B} 1 \mathrm{C} 1$ & & - & $39,900 \mathrm{e}$ & - \\
\hline $\mathrm{B} 2 \mathrm{C} 0$ & & $3.298 \mathrm{c}$ & $61,215 \mathrm{~b}$ & 0.355 \\
\hline $\mathrm{B} 2 \mathrm{C} 1$ & & - & - & - \\
\hline \multicolumn{5}{|c|}{ Interaksi Giberellin, Asam Salisilat dan Cekaman Salinitas } \\
\hline $\mathrm{A} 0 \mathrm{~B} 0 \mathrm{C} 0$ & & $3.554 \mathrm{c}$ & $67,350 \mathrm{~d}$ & 0.219 \\
\hline $\mathrm{A} 0 \mathrm{~B} 0 \mathrm{C} 1$ & & - & - & - \\
\hline $\mathrm{A} 0 \mathrm{~B} 1 \mathrm{C} 0$ & & $3.704 \mathrm{~b}$ & 63,140 e & 0.297 \\
\hline $\mathrm{A} 0 \mathrm{~B} 1 \mathrm{C} 1$ & & - & - & - \\
\hline $\mathrm{A} 0 \mathrm{~B} 2 \mathrm{C} 0$ & & $3.214 \mathrm{f}$ & $74,870 \mathrm{c}$ & 0.306 \\
\hline $\mathrm{A} 0 \mathrm{~B} 2 \mathrm{C} 1$ & & - & - & - \\
\hline $\mathrm{A} 1 \mathrm{~B} 0 \mathrm{C} 0$ & & $3.384 \mathrm{~d}$ & $46,820 \mathrm{~h}$ & 0.333 \\
\hline A1B0C1 & & - & $93,100 \mathrm{a}$ & - \\
\hline $\mathrm{A} 1 \mathrm{~B} 1 \mathrm{C} 0$ & & $3.874 \mathrm{a}$ & $61,310 \mathrm{f}$ & 0.292 \\
\hline $\mathrm{A} 1 \mathrm{~B} 1 \mathrm{C} 1$ & & - & $79,800 \mathrm{~b}$ & - \\
\hline $\mathrm{A} 1 \mathrm{~B} 2 \mathrm{C} 0$ & & $3.381 \mathrm{e}$ & $47,560 \mathrm{~g}$ & 0.403 \\
\hline $\mathrm{A} 1 \mathrm{~B} 2 \mathrm{C} 1$ & & - & - & - \\
\hline
\end{tabular}

Keterangan : Angka pada kolom dan baris yang sama yang diikuti oleh huruf yang sama tidak berbeda nyata pada taraf 5\% berdasarkanuji DMRT (Duncan Multiple Range Test)

Ali et al (2011), menyatakan bahwa aplikasi $\mathrm{GA}_{3}$ mengurangi efek penghambatan $\mathrm{NaCl}$ pada berberapa parameter pertumbuhan dan pigmen fotosintesis pada Hibiscus sabdariffa dengan menginduksi aktivitas enzim dan meningkatkan RWC (kadar air relatif) dan dengan demikian $\mathrm{GA}_{3}$ membantu dalam toleransi tanaman terhadap stres garam. Hal ini juga didukung dengan pernyataan Davies (1995), yang menyatakan bahwa gibberellin memproduksi enzim selama perkecambahan, giberellin merangsang produksi berbagai enzim, terutama amilase, contoh pada perkecambahan biji-bijian sereal.

2. Pengaruh Interaksi Antara Perlakuan Asam Salisilat Dan Cekaman Salinitas 
Pada penelitian ini interaksi antara perlakuan asam salisilat dan cekaman salinitas memperlihatkan pengaruh menurunkan tebal kutikula (Tabel), yaitu pemberian asam salisilat $(0,5 \mathrm{mM})$ pada kondisi cekaman salinitas pada tanaman menurunkan tebal kutikula. Walaupun tanaman rosella tidak mampu bertahan di tanah salin sampai fase generatif. Hal ini disebabkan karena pada penelitian ini sebagian dari tanaman rosella yang mendapatkan perlakuan cekaman salinitas mengalami kematian sehingga menurunkan rataan tebal kutikula, namun jika dilihat dari rataan tanaman yang mampu bertahan dihasilkan peningkatan tebal kutikula yang paling tebal terdapat pada tanaman rosella yang mendapat perlakuan cekaman salinitas.

Tebal kutikula merupakan faktor pentingdalam menjagakadar airrelatif daun dan varietas itu menunjukkan ketebalan yang lebih besar dari kutikula daun, dalam kondisi kering, mempertahankan kadar air relatif tinggi dalam daun mereka dan lebih tahan terhadap kekeringan. Rasuli and GolMohammadi (2009) menyatakan bahwa ketebalan kutikula daun, langsung berkorelasi dengan toleransi kekeringan dan meningkatkan dengan meningkatnya stres air dan dapat digunakan sebagai penanda untuk identifikasi varietas tahan. Disamping itu, beberapa studi menunjukkan bahwa aplikasi SA $(0,5 \mathrm{mM})$ dapat mempromosikan pembentukan ROS pada jaringan fotosintesis dan menyebabkan kerusakan oksidatif selama cekaman garam dan tekanan osmotik (Barba-Espin et al. 2011).

\section{Pengaruh Interaksi Tiga Faktor Perlakuan Giberellin, Asam Salisilat Dan Cekaman Salinitas Terhadap Pertumbuhan Rosella}

Pada peneitian ini, interaksi pemberian giberellin $\left(5 \mathrm{mg} \mathrm{L}^{-1}\right)$ dan asam salisilat $\quad(0,5 \mathrm{mM})$ pada kondisi cekaman salinitas meningkatkan tebal kutikula, jika dibandingkan dengan tanpa pemberian gibberellin dan asam salisilat (Tabel). Salinitas menyebabkan perubahan morfologi daun seperti ukuran daun, luas dan ketebalan. Berbagai penelitian telah melaporkan penurunan ukuran daun dan peningkatan ketebalan kutikula daun (Terrv and Waldron. 1984). Hal senada dikemukakan oleh Hajibagheri et al. (1983), yang menyatakan bahwa pengamatan pada salinitas yang tinggi secara signifikan meningkatkan ketebalan kutikula. Salinitas tidak hanya mempengaruhi morfologi daun dan laju transpirasi tetapi juga mengarah pada pengurangan kandungan total klorofil seperti meningka tkonsentrasi garam.El Tayeb (2005) menemukan bahwa aplikasi SA untuk jelai memicu respon pre - adaptif terhadap stres garam, meningkatkan sintesis Chl a, b dan Chl Car, dan mempertahankan integritas membran yang menyebabkan peningkatan pertumbuhan tanaman.

\section{SIMPULAN}

Pemberian giberellin $\left(5 \mathrm{mg} \mathrm{L}^{-1}\right)$ pada kondisi cekaman salinitas pada tanaman rosella membantu mempertahankan keberhasilan perkecambahan walaupun tebal kutikula menurun dan tidak terbentuk bunga (fase generatif) untuk dipanen.

Pemberian asam salisilat $(0,5 \mathrm{mM})$ pada kondisi cekaman salinitas $\left(4-5 \mathrm{dsm}^{-1}\right)$ pada tanaman rosella belum dapat meningkatkan tebal kutikula.

Interaksi pemberian giberellin (5 $\left.\mathrm{mg} \mathrm{L}^{-1}\right)$ dan asam salisilat $(0,5 \mathrm{mM})$ pada kondisi cekaman salinitas $\left(4-5 \mathrm{dsm}^{-1}\right)$ dapat meningkatkan tebal kutikula jika dibandingkan dengan tanpa pemberian gibberellin dan asam salisilat.

\section{DAFTAR PUSTAKA}

Ali. H.M.,M.H. Siddiqui., M.O. Basalah., M.H. Al-Whaibi., A.M. Sakran and 
A. Al-Amri. 2011. Effects ofgibberellic acid on growth and photosynthetic pigments of Hibiscus sabdariffaL. under saltstress. Afr J Biotechnol 11:800804.

Almansouri, M., J.M. Kinet and S. Lutts. 2001.Effect of salt and osmotic stresses on germination in durumwheat (Triticumaestivum). Plant Soil, 231: 243-254.

Barba-Espin G., M.J. Clemente-Moreno., S. Alvarez., M.F. Garcia-Legaz., J.A. Hernandez and P. DiazVivancos. 2011. Salicylic acid negatively affects the response to salt stress in pea plants. Plant Biol13:909-917.

Chen, C.C., J.D. Hsu, S.F. Wang, H.C. Chiang, M.Y. Yang and E.S. Kao, 2002. Hibiscus Sabdariffaextractinhibits the development of atherosclerosis in cholesterol-fed rabbits. J. Agric. food Chem., 51: 5472-5477.

Davies, P. J. 1995. Plant Hormones, Physiology, Biochemistry and Molecular Biology. $2^{\text {nd }}$ edition.Kluwer Academic Publishers. Netherlands.

Departemen Pekerjaan Umum. 1997. Kebijaksanaan Pembangunan Irigasi Dalam Peningkatan Produksi Pangan (Formulasi Program Pengembangan Irigasi pada PJP II). Direktorat Bina Teknik Jenderal Pengairan Departemen Pekerjaan Umum.

El Tayeb. M.A. 2005. Response of barley grains to the interactive effect of salinity and salicylicacid. Plant Growth Regul 45:215-224.

FAO, 2005. Global network on integrated soil management for sustainable use of salt affected soils, Rome, Italy: FAO Land and Plant Nutrition Management Service.

Hajibagheri M. A., J. L. Hall and T. J. Flowers. 1983. The structureof the cuticle in relation to cuticular transpiration in leaves of thehalophyte suaedamaritima (L.) Dum, New Phytologist, 94(1),125131.

Hasanuzzaman, M., K. Nahar and M. Fujita. 2013. Plant Response to Salt Stress and Role of Exogenous Protectants to Mitigate Salt-Induced Damage. Spriger Science Busines Media.

Lin, T., H. Lin, C. Chen, M. Lin, M. Chou and C. Wang, 2007.Hibiscus Sabdariffaextract reduces serumcholesterol in men and women. Nutr Res., 27: 140-145.

Magome, H., S. Yamaguchi., A. Hanada., Y. Kamiya and K. Odadoi. 2004. Dwarf and delayed flowering, a novel Arabidopsis mutant deficient in gibberellins biosynthesis because of overexpressionof a putative AP2 transcription factor. Plant J 37:720729.

Moosavi, S.G., M.J. Saghatoleslami., H. Javadi., S.M. Moosavi., Z. Jouyban., E. Ansarina and M. Nasiri. 2013. Effect of Salt Stress on Germination and Early Seedling Growth of Roselle (Hibiscuss sabdariffa). Global Journal of Madicine Plant Research, 1(1):124127,2013.

Morton, J.F. 1987. Roselle. In: Morton JF, Dowling CF, (eds). Fruits of warm climates.Miami, Florida Flair Books. Pp: 281-286. [cited 2007 Nov 17]. URL: www.Hort.purdue.edu/newcrop/M orton/roselle.html.

Rasuli, and M. Gol-Mohammadi. 2009. Evaluation of drought tolerance in grapevines Qazvin. Seed and PlantJournal 1-25: 395-349.

Sakhabutdinova, A.R., D.R. Fatkhutdinova., M.V. Bezrukova and F.M. Shakirova. 2003. Salicylic acid preventsthe damaging action of stress factors on wheat plants. Bulg J Plant Physiol 314-319. 
Seghatoleslami, M.J., 2010. Effect of salinity on germination of SaturejahortensisL., CichoriumintybusL. and CynarascolymusL. Iranian Journal of Agricultural Researches.

Soltani, A., M. Gholopoor and E. Zeinali, 2006. Seed reserve utilization and seedling growth of wheat asaffected by drought and salinity. Environ. Exp. Bot., 55: 195-200.

Sundstrom F. J., R. B. Reader and R.L. Edwards. 1987. Effect of Seed Treatment and Planting Method on Tobasco Pepper. J Am Soc Hort Sci 112:641-644.
Terrv N. and L. J. Waldron. 1984. Salinity, photosynthesis and leafgrowth, California Agricult., 38-39.

Yusuf, M., Q. Fariduddin., P. Varshney and A. Ahmad.2012. Salicylic acid minimizes nickel and/orsalinityinduced toxicity in Indian mustard (Brassicajuncea) through an improved antioxidantsystem. Environ SciPollut Res 19:8-18. 